\title{
Penerapan Metode Eigenface dan Pemanfaatan Database Fg-Net untuk Mengetahui Usia Manusia Berdasarkan Wajah
}

\author{
IRMA AMELIA D, YOULLIA INDRAWATY N, DIAN PURNOMO
}

\author{
Jurusan Teknik Informatika, Fakultas Teknologi Industri \\ Institut Teknologi Nasional Bandung \\ Email: irma_amelia@itenas.ac.id
}

\begin{abstract}
ABSTRAK
Wajah merupakan salah satu ciri pada manusia untuk dapat dibedakan satu sama lain. Terdapat beberapa faktor yang mendasari perbedaan setiap wajah manusia yaitu genetik, jenis kelamin, etnis dan usia. Seiring berjalannya waktu, wajah manusia mengalami beberapa perubahan akibat bertambahnya usia. Perubahan yang sering kali terjadi seperti penambahan garis halus pada wajah atau terdapat perubahan kontur pada wajah, hal tersebut dapat dijadikan acuan untuk mengidentifikasi usia. Oleh karena itu, pada penelitian melakukan pendeteksian usia berdasarkan wajah. Metode yang digunakan yaitu Eigenface didasarkan pada metode statistik Principal Component Analysis (PCA) dengan menggunakan database fg-net yang berisi titik ciri dari citra wajah yang sudah diketahui usianya. Eigenvector dari Matriks fitur wajah data uji dibandingkan dengan eigenvector matriks dari database fg-net citra latih untuk menentukan kecocokan usia. Hasil pengujian usia berdasarkan citra wajah yang berasal dari 30 orang mencapai tingkat akurasi sebesar 56,66\%.
\end{abstract}

Kata Kunci: Eigenface, FG-Net, Usia, Deteksi Wajah

\section{ABSTRACT}

The face is one of the human characteristics to distinguish one from another. There are several factors that underlie differences in each human face, namely genetic, gender, ethnicity, and age. Over time, the human face undergoing some changes due to aging. The changes often occur as the addition of fine lines on the face or change the contours of the face can be used as a reference for identifying the age. Therefore, the research conducted detection of face-based age. The method used is Eigenface, based on the Principal Component Analysis (PCA) statistical method using the FG-net database. the FG database contains images from users whose age is known. Eigenvector of the Matrix facial feature of the test data was compared with the Eigenvector matrix of the FG-net image training database to determine the age match. The test results of the age detection system based on facial images from 30 people reached an accuracy level of $56.66 \%$.

Keywords : Eigenface, FG-Net, Age, Face Detection 


\section{PENDAhUlUAN}

Pengenalan wajah merupakan ciri unik yang dimiliki oleh manusia yang dapat digunakan pada sistem pendeteksian usia. Pengenalan wajah dapat difungsikan pada aplikasi pendekteksian identitas sesorang. Dengan berjalannya waktu, wajah seseorang akan mengalami perubahan. Perubahan yang terjadi pada wajah seseorang terutama disebabkan oleh tiga alasan utama yakni usia, jenis kelamin dan kelompok etnis. Usia tampaknya menjadi penyebab utama dalam perubahan wajah manusia, pernyataan ini banyak diutarakan dalam berbagai penelitian ilmiah.

Dengan adanya keunikan pada wajah, maka wajah dapat diimplementasikan dalam bidang pendidikan maupun bidang pekerjaan yang dapat difungsikan pada aplikasi. Sistem identifikasi ciri pola wajah dua proses yaitu proses ekstraksi dengan eigenface dan proses klasifikasi dengan database fg-net. Proses pencocokan menggunakan eigenface bertujuan untuk menghitung nilai matrik, nilai egen vektor, nilai eigenface, dan mendapatkan nilai pca. Proses klasifikasi menggunakan database fg-net yang dimana proses klasifikasi menggunakan algoritma euclidean distance dimana hasil dari data uji dan data latih yang baru diklasifikasikan berdasarkan citra wajah dari kategori jumlah objek. Dimana klasifikasi menggunakan perhitungan jarak terdekat antara citra latih dan citra uji digunakan perhitungan euclidean distance.

Sistem ini dibuat dengan data masukan berupa citra wajah seseorang, data pengambilan citra garis telapak tangan dilakukan dengan posisi tangan dalam kondisi tegak $90^{\circ}$, jarak pengambilan data latih yaitu $50 \mathrm{~cm}$ dari kamera dan data uji yaitu $50 \mathrm{~cm}$ sehingga dari kamera dan sistem akan menghasilkan identifikasi berupa identitas wajah sesorang.

\section{METODOLOGI PENELITIAN}

Aplikasi identifikasi citra wajah memiliki dua proses untuk melakukan identifikasi yaitu proses ekstraksi dan proses klasifikasi. Hasil akhir sistem identifikasi diimplementasikan sebagai sistem berupa identitas wajah seseorang.

Proses ekstraksi dilakukan dengan menggunakan metode eigenface untuk menghitung nilai matrik, matrik kovarian, eigen vektor, eigenface, dan nilai PCA. Ekstraksi eigenface menggunakan proses reduksi untuk mengetahui nilai matrik. Semakin besar nilai pixel uji yang didapat maka tingkat kecocokan semakin tinggi dengan pixe/latih.

Eigenface merupakan metode yang digunakan untuk mengambil ciri-ciri penting dari sekumpulan citra yang mempunyai pencahayaan yang merata dengan melakukan dekomposisi terhadap data citra wajah sehingga menghasilkan koefisien-koefisien yang tidak saling berkorelasi. Metode Eigenface didasarkan pada metode statistik Principal Component Analysis (PCA) yang digunakan untuk pencarian pola wajah.

Pendekatan metode Eigenface melibatkan proses-proses sebagai berikut pada tahap inisialisasi :

1. Pengumpulan sejumlah citra yang digunakan sebagai citra latih menggunkan Persamaan (1) [1]. 


$$
M=(\text { sum_baris_ke_i) / (jml_baris_ke_i) }
$$

Keterangan :

$$
\text { M : Jumlah image }
$$

2. kemudian langkah berikutnya adalah melakukan pengurangan tiap nilai dalam matriks $T$ dengan nilai rata-rata dan setelah itu dimasukkan ke dalam matrik $A$, menggunakan Persamaan (2)

Keterangan :

$$
A=T-M
$$

A : adalah selisih matriks

$\mathrm{T}$ : Matrik

M : Nilai mean

3. Menentukan nilai matrik, dengan menghitung matriks kovarian $L$ dengan cara mengubah matriks menjadi matrik transposenya $(T)$, menggunakan Persamaan (3)

$$
L=T \times A
$$

Keterangan :

T : Matriks kovarian

A : selisih matriks

4. Menghitung vektor eigen, Persamaan (4)

$$
\text { Eigenfaces }=\mathrm{A} \times \mathrm{V}
$$

Keterangan:

A: matriks

$\mathrm{V}$ : vektor iegen

Nilai vektor eigen adalah nilai eliminasi dari kovarian matrik $L$

5. Menghitung nilai PCA pada citra data latih dengan menggunakan Persamaan (5)

$$
\text { PCA_train = eigenfaces } \times \mathrm{A}
$$

6. Nilai difference diperoleh setelah citra diketahui nilai rata-ratanya seperti pada langkah 1 menggunakan Persamaan (6)

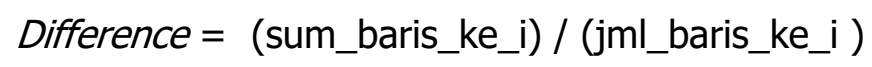

7. Menghitung nilai PCA citra uji untuk diproyeksikan ke fitur ruang wajah pengguna menggunakan Persamaan (7)

$$
\text { PCA_test }=\text { eigenfaces } x \text { diffrence }
$$

Proses klasifikasi menggunakan metode Euclidean distance yang sebelumnya menghitung rata-rata setiap nilai pixe/ kemudian dilakukan perhitungan jarak antara hasil ekstraksi dari PCA data uji dengan semua data latih. Jarak yang telah diperoleh akan diurutkan berdasarkan nilai jarak terdekat, untuk menentukan klasifikasi usia seseorang.

Salah satu pengukuran yang paling banyak digunakan untuk menghitung kedekatan jarak atau biasa disebut dengan euclidean distance. menggunakan Persamaan (8) [2] 


$$
D=\sqrt{\sum_{i=1}^{n}\left(P C A_{\text {test }} i-P C A_{\text {train }} i\right)^{2}}
$$

Keterangan:

PCA_test $=$ nilai ciri citra uji

PCA_train = nilai ciri citra data latih

Pada penelitian ini mengunakan Database FG-NET yang memuat titik-titik ciri penting dari pola bentuk wajah yang dapat digunakan untuk kebutuhan identifikasi wajah, salah satunya dapat digunakan untuk menentukan usia seseorang. Database ini dikembangkan dengan menentukan titik-titik ciri penting dari wajah dengan menggunakan sumber panduan penentuan titik-titik ciri wajah dari FG-net (Face and Gesture Recognition Research Network) Aging Database.

\section{ANALISIS DAN PEMBAHASAN}

Untuk menggambarkan langkah-langkah dan urutan prosedur dari aplikasi Pengenalan wajah untuk menentukan usia secara umum maka dibuat sebuah model kerja sistem aplikasi secara umum seperti pada Gambar 1.

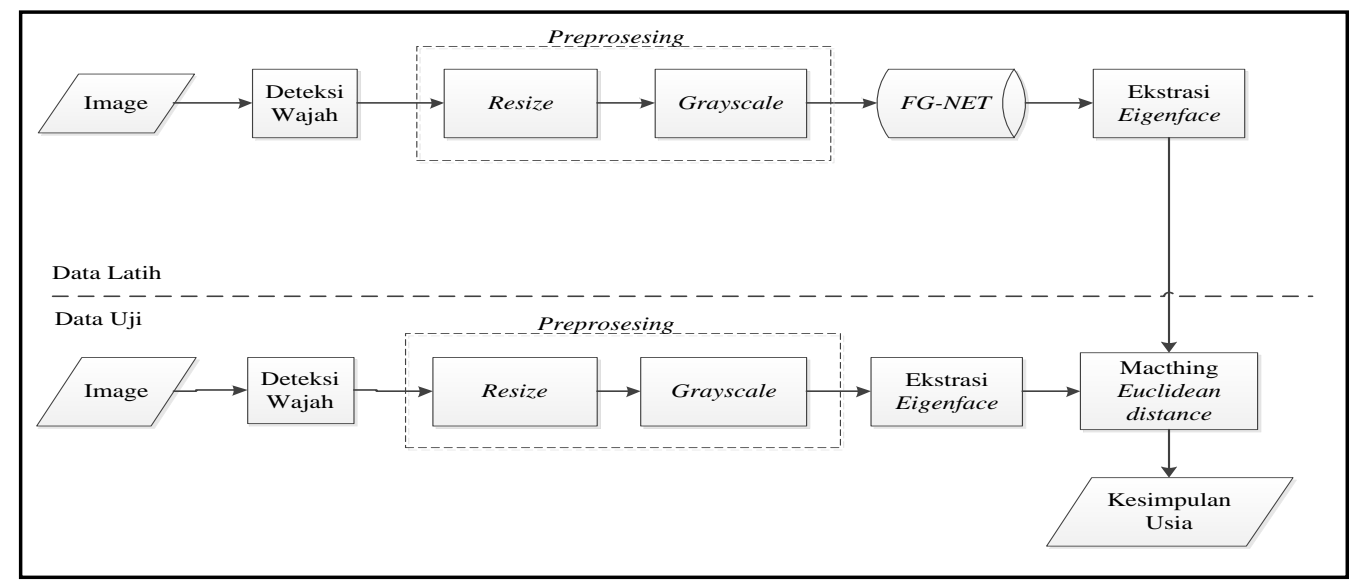

Gambar 1. Tahapan cara kerja sistem

Sistem dibagi menjadi dua tahap proses yaitu proses pendaftaran dan proses klasifikasi. Pada proses pendaftaran dan klasifikasi memiliki tahapan yang sama dari tahap akuisisi citra sampai ektraksi ciri.

Akuisisi citra merupakan cara untuk mendapatkan karakteristik dari biometrika wajah. Citra masukan yang dapat diperoleh dengan dua cara yaitu menggunakan perangkat tambahan (Webcam) atau mengambil citra pada direktori

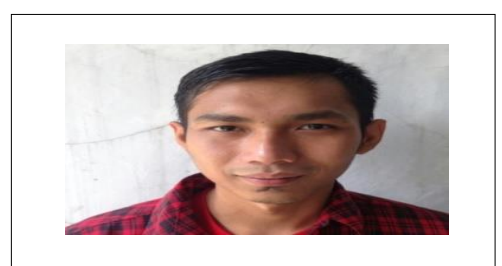

\section{Gambar 2. Contoh citra wajah yang dapat diolah}

Citra latih dan uji yang digunakan dilakukan proses resize menjadi 168x168 piksel agar memiliki ukuran citra yang sama seperti pada Gambar 3. 


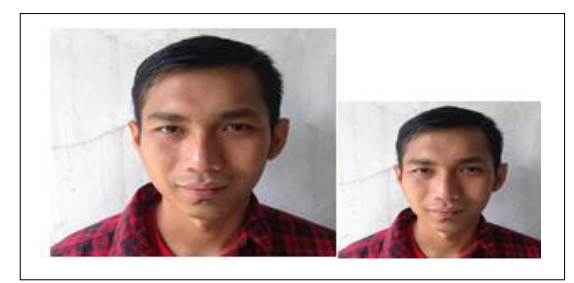

Gambar 3. Contoh citra resize

Dalam penelitian ini, prapemrosesan terdiri dari konversi citra wajah berwarna(RGB) ke citra grayscale. Citra yang dihasilkan pada tahap akuisisi citra adalah citra berwarna sehingga perlu dikonversi ke citra grayscale [3] seperti pada Persamaan (9).

$$
G=0.2126 * R+0.7152 * G+0.0722 * B
$$

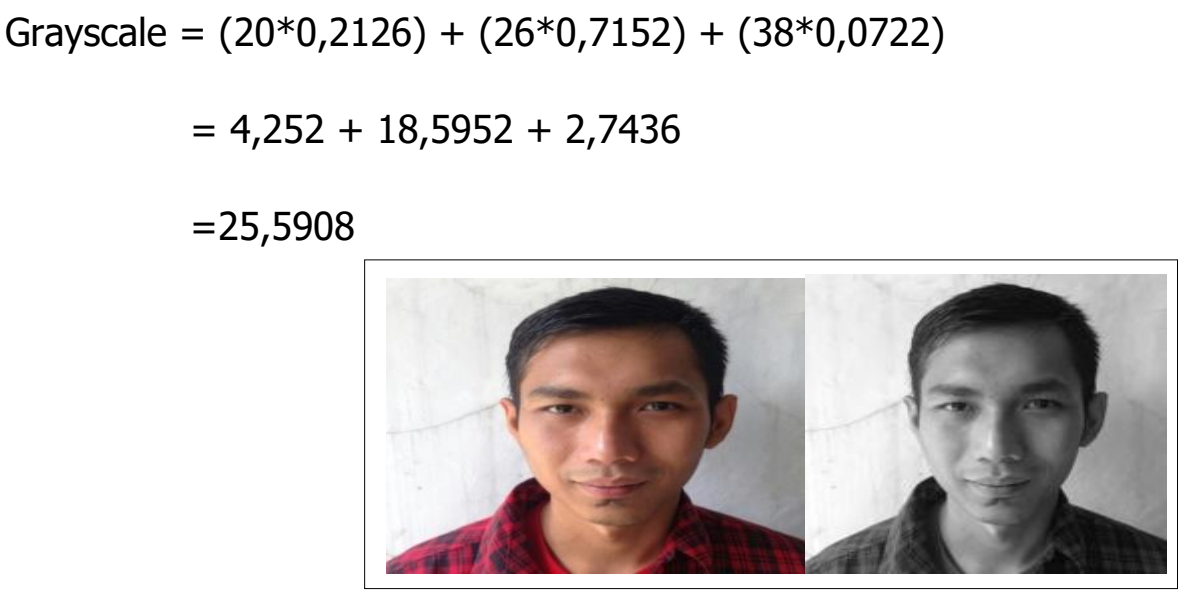

\section{Gambar 4. Konversi Citra RGB ke Grayscale}

Berikutnya ciri dari citra wajah dihitung dengan mencari nilai mean matrik, matrik kovarian, eigen vektor, eigenface, dan nilai pca_test. Pertama adalah melakukan reduksi dimensi citra 2D pada data training menjadi citra 1D. Misalkan pada contoh Gambar. 5 nilai piksel pada koordinat $(0,0),(0,1)$ sampi dengan $(3,2)$ atau dimulai dari posisi ujung kiri atas akan ditranlasika ke dimensi citra $1 \mathrm{D}$ dengan posisi citra $(0,0)$ berada di posisi koordinat $(0)$ atau paling atas.

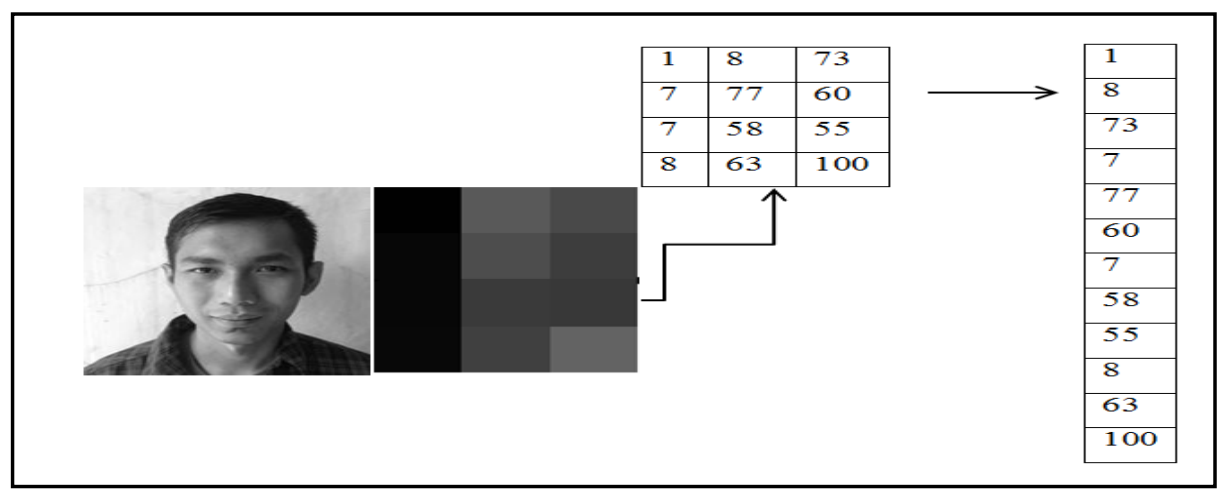




\section{Gambar 5. Reduksi dimensi citra}

1. Menghitung nilai mean citra

Proses menghitung rata-rata nilai dari matriks citra yang telah diubah menjadi 1 dimensi dengan menggunakan Persamaan (1). Berikut ini adalah contoh perhitungan mean citra dari citra yang telah diubah menjadi citra 1 dimensi seperti pada Tabel 1:

Tabel 1. Contoh data citra 1D

\begin{tabular}{|l|l|l|l|l|}
\hline Citra ke-1 & Citra ke-2 & Citra ke-3 & Citra ke-4 & Citra ke-5 \\
\hline 225 & 192 & 1 & 84 & 228 \\
\hline 212 & 222 & 8 & 73 & 208 \\
\hline 223 & 225 & 73 & 58 & 221 \\
\hline 225 & 221 & 7 & 74 & 226 \\
\hline 113 & 178 & 77 & 72 & 139 \\
\hline 171 & 220 & 60 & 64 & 174 \\
\hline 217 & 217 & 7 & 71 & 120 \\
\hline 125 & 130 & 58 & 74 & 136 \\
\hline 185 & 191 & 55 & 71 & 179 \\
\hline 115 & 140 & 8 & 85 & 136 \\
\hline 70 & 80 & 63 & 80 & 93 \\
\hline 120 & 123 & 100 & 73 & 109 \\
\hline
\end{tabular}

$$
\begin{aligned}
M_{(\text {citra- } 1)} & =\frac{(225+212+223+225+113+171+217+125+185+115+70+120)}{12} \\
& =\frac{(2001)}{12} \\
& =166.75
\end{aligned}
$$

Berikutnya menghitung selisih nilai piksel pada citra yang telah diubah menjadi 1 dimensi dengan nilai rata-rata citranya menggunakan Persamaan (2).

$$
\begin{aligned}
A & =225-166.75 \\
& =58.25
\end{aligned}
$$

Nilai A digunakan untuk mencari nilai matriks kovarian $L$ menggunakan Persamaan (3):

$$
\begin{aligned}
\mathrm{L} & =225 \times 58.25 \\
& =13106.25
\end{aligned}
$$

Nilai eigenface pada proses ini merupakan nilai ciri citra data training. Nilai ini dihitung menggunakan persamaan (4):

$$
\begin{aligned}
\text { Eigenface } & =\mathrm{A} \times \mathrm{V} \\
& =58.25 \times-6073.75 \\
& =-353795.937
\end{aligned}
$$

Menghitung nilai PCA_train Setelah nilai eigenfaces diperoleh, kini tugas dari PCA untuk mereduksi ciri yang masih terdapat pada citra data training. Hasil dari reduksi ini yaitu berupa pengurangan dimensi data, jadi nilai yg diambil adalah nilai yang terkecil dari matriks A. Berikut ini persamaan yang digunakan untuk mencari nilai PCA citra data training menggunakan persamaan (5):

$$
\begin{aligned}
\text { PCA_train } & =-353795.937 \times-53.75 \\
& =19016531.613
\end{aligned}
$$

menghasilkan nilai difference seperti pada langkah 1, menggunakan Persamaan (6): Difference $=\frac{19016531.613+9859197.244+17233716.771+38167693.593+(-14096878.125)}{5}$

$$
\text { MIND - } 47
$$




$$
=14036052.219
$$

Menghitung nilai PCA_test citra yang diuji ambil nilai terkecil dari nilai eigenface dengan menggunakan Persamaan (7):

$$
\begin{aligned}
\text { PCA_test } & =-394498.125 \times 14036052.219 \\
& =-5537194528291
\end{aligned}
$$

Nilai yang diambil dari PCA_test dan PCA_train adalah nilai yang terkeil. Pada dasarnya pengukuran jarak digunakan untuk menghitung perbedaan antara dua vektor citra dalam ruang eigen, dengan menggunakan persamaan (8):

$$
\begin{aligned}
\text { Euclidean distance }= & -5537194528291-(-14036052.219) \\
& =-5537180492238.7
\end{aligned}
$$

\section{Pengujian}

Pengujian aplikasi pengenalan wajah untuk mengetahui usia seseorang dengan mengimplementasikan algoritma Eigenface dan database FG-NET dilakukan kepada oleh developer (uji alpha) dengan uji fungsi (uji blackbox). Jumlah Sampel yang digunakan adalah 30 orang yang terdiri dari usia 18 tahun sampai dengan 24 tahun. Masing - masing sampel diambil citra wajahnya kemudian dilakukan pengujian pencocokan terhadap data latih yang sudah disimpan didalam database.

Data pada tabel 1 merupakan hasil proses data pengujian dengan usia 24 tahun dimana dilakukan 10x pengujian kecocokan.

Tabel 1 Pengujian dengan usia 24 tahun

\begin{tabular}{|c|c|c|c|}
\hline Usia & Pengujian & $\begin{array}{c}\text { Usia yang } \\
\text { terdeteksi }\end{array}$ & Kesimpulan \\
\hline 24 & Pengujian1 & 26 & Salah \\
\cline { 2 - 4 } & Pengujian2 & 24 & Senar \\
\cline { 2 - 4 } & Pengujian3 & 28 & Benar \\
\cline { 2 - 4 } & Pengujian4 & 24 & Salah \\
\cline { 2 - 4 } & Pengujian5 & 25 & Benar \\
\cline { 2 - 4 } & Pengujian6 & 24 & Benar \\
\cline { 2 - 4 } & Pengujian7 & 24 & Salah \\
\cline { 2 - 4 } & Pengujian8 & 28 & Benar \\
\cline { 2 - 4 } & Pengujian9 & 24 & Benar \\
\cline { 2 - 4 } & Pengujian10 & 24 & \\
\hline
\end{tabular}

Hasil akurasi pada pengujian usia 24 tahun didapatkan persentase sebesar $60 \%$. Berikut adalah perhitungannya:

$\frac{6}{10} \times 100=60 \%$

Data pada Tabel 2 didapatkan hasil proses data pengujian dengan usia 23 tahun dilakukan 10x pengujian kecocokan. 
Tabel 2 Hasil Pengujian dengan usia 23 tahun

\begin{tabular}{|c|c|c|c|}
\hline Usia & Pengujian & $\begin{array}{c}\text { Usia yang } \\
\text { terdeteksi }\end{array}$ & Kesimpulan \\
\hline 23 & Pengujian1 & 23 & Benar \\
\hline & Pengujian2 & 24 & Salah \\
\hline & Pengujian3 & 23 & Benar \\
\hline & Pengujian4 & 23 & Benar \\
\hline & Pengujian5 & 25 & Salah \\
\hline & Pengujian6 & 23 & Benar \\
\hline & Pengujian7 & 24 & Salah \\
\hline & Pengujian8 & 28 & Salah \\
\hline & Pengujian9 & 23 & Benar \\
\hline & Pengujian10 & 24 & Salah \\
\hline
\end{tabular}

Hasil akurasi pada pengujian dengan usia 23 tahun didapatkan persentase sebesar $50 \%$. Berikut adalah perhitungannya:

$$
\frac{5}{10} \times 100=50 \%
$$

Data pada Tabel 3 didapatkan hasil proses data pengujian dengan usia 18 tahun samapi 24 tahun berikut pengujian.

Tabel 3 Hasil Pengujian tidak langsung

\begin{tabular}{|c|c|c|c|}
\hline Nama & Usia & $\begin{array}{c}\text { Usia yang } \\
\text { terdeteksi }\end{array}$ & $\begin{array}{c}\text { Kesimp } \\
\text { ulan }\end{array}$ \\
\hline Deva & 18 & 22 & Salah \\
\hline Susi & 18 & 18 & Benar \\
\hline Dewi & 18 & 21 & Salah \\
\hline Roni & 18 & 18 & Benar \\
\hline Evi & 18 & 20 & Salah \\
\hline Reni & 19 & 19 & Benar \\
\hline Agus & 19 & 18 & Salah \\
\hline Fendi & 19 & 23 & Salah \\
\hline Yani & 19 & 19 & Benar \\
\hline Rezaldy & 19 & 19 & Benar \\
\hline
\end{tabular}

\begin{tabular}{|c|c|c|c|}
\hline Maya & 20 & 23 & Salah \\
\hline Gladys & 20 & 20 & Benar \\
\hline Galih & 20 & 19 & Salah \\
\hline Eka & 20 & 20 & Benar \\
\hline Budi & 20 & 23 & Salah \\
\hline Yuda & 21 & 21 & Benar \\
\hline Yeni & 21 & 24 & Salah \\
\hline Winda & 21 & 21 & Benar \\
\hline Santi & 21 & 19 & Salah \\
\hline Bagas & 21 & 21 & Bemar \\
\hline Toni & 22 & 20 & Salah \\
\hline Putri & 22 & 22 & Benar \\
\hline
\end{tabular}


Dewi, dkk

\begin{tabular}{|c|c|c|c|}
\hline Febri & 22 & 24 & Salah \\
\hline Ahmad & 22 & 21 & Salah \\
\hline Adrian & 22 & 22 & Benar \\
\hline Yanti & 23 & 23 & Benar \\
\hline Rifki & 23 & 26 & Salah \\
\hline Joko & 23 & 25 & Salah \\
\hline Eka & 23 & 23 & Benar \\
\hline Arif & 23 & 20 & Salah \\
\hline Zul & 24 & 26 & Benar \\
\hline Sabar & 24 & 26 & Salah \\
\hline Dian & 24 & 24 & Benar \\
\hline Maya & 24 & 22 & Salah \\
\hline Feply & 24 & 28 & Salah \\
\hline
\end{tabular}


Hasil akurasi pada pengujian 30 orang sample dengan usia 18 tahun sampai 24 tahun didapatkan persentase sebesar $56.66 \%$. Berikut adalah perhitungannya:

$$
\frac{17}{30} \times 100=56.66 \%
$$

\section{KESIMPULAN}

Berdasarkan hasil pengujian sistem yang telah dilakukan, maka didapatkan kasimpulan bahwa sistem aplikasi menentukan usia berdasarkan citra wajah dapat diimplementasikan dengan metode Eigenface dan pemanfaatan database FG-NET. Aplikasi ini mampu menentukan hasil usia sesorang dengan mencocokanya citra wajah yang berada dalam database FG-NET. Hasil dari pengujian langsung pada dengan usia 24 tahun yang dilakukan sebanyak 10 kali pengujian menghasilkan tingkat akurasi sistem adalah $60 \%$, dan pengujian langsung pada usia 23 tahun yang dilakukan sebanyak 10 kali pengujian menghasilkan tingkat akurasi sistem mencapai $50 \%$. Hasil pengujian tidak langsung yang dilakukan pada 30 sample dengan usia 18 tahun sampai 24 tahun didapatkan tingkat akurasi sistem mencapai $56.66 \%$.

\section{DAFTAR PUSTAKA}

[1] M. Dwisnanto Putro, Teguh Bharata Adji, Bondhan Winduratna, 2012. Sistem Deteksi Wajah dengan Menggunakan Metode Viola-Jones. Yogyakarta. Universitas Gajah Mada.

[2] Fadlisyah, S.Si., MT., 2013. Sistem Pendektesian Wajah Pada Video Menggunakan Jaringan Adaptive Linear Neuron (ADALINE). Medan. Universitas Sumatra Utara.

[3] Esty Vidyaningrum, Prihandoko, 2009. Pembuatan Aplikasi Deteksi Wajah Pada Citra Digital Menggunakan Metode Eigenface Untuk Berbagai Pose Wajah Manusia. Depok. Gunadarma University.

[4] Setya Bayu, 2010. Akhmad Hendriawan, Ronny Susetyoko, Penerapan Face Recognition Dengan Metode Eigenface Dalam Intelligent Home Security. Surabaya. Institut Teknologi Sepuluh Nopember(ITS).

[5] Bruce Bradtmiller, Ph.D, Martin Friess, Ph.D, 2004. A Head-And-Face Antropometric Survey Of U.S. Respirator Users. United States. Xenia Avenue.

[6] Alfin sholeh, 2013. Pengembangan Sistem Pengenalan Wajah 2D Dengan Implementasi Algoritma Eigenface Dan Manhattan Ditance. Bandung Universitas Pendidikan Indonesia.

[7] Nur Fitrianti Fahrudin, Muhammad Ichwan, Andriana, 2015. Pengenalan Wajah Dengan Ekstraksi Filter Gabor Dan Metode support Vector Machine Untuk Klasifikasi Gender. Bandung. Program Studi Teknik Informatika Fakultas Teknik Industri Institut Teknologi Nasional.

[8] Putra Darma, 2009,Sistem Biometrika Konsep Dasar, Teknis Analisis Citra, dan Tahapan Membangun Aplikasi Sistem Biometrika, Andi Yogyakarta.

[9] Alfin Sholeh, 2013. Pengembangan Sistem Pengenalan Wajah 2D Dengan Implementasi Algoritma Eigenface Dan Manhattan Distance 